\title{
LINGUAGEM E SUJEITO
}

\section{Paulo Juarez Rueda Strogenski}

De maneira geral, os estudos da linguagem sempre se preocuparam mais com a linguagem como um produto acabado, isento das suas condições de produção. O Estruturalismo, inspirado em Saussure, nunca considerou o falante como elemento importante na produção lingüística. $O$ objeto de estudo dos estruturalistas sempre foi a língua por ela mesma. A sua intenção era simplesmente a de descrever os diversos sistemas lingüísticos, independentemente das condições de produção ou até mesmo dos falantes que deles faziam uso. Se por um lado essa postura proporcionou à lingüística o status de ciência formalmente constituída, por outro acabou gerando uma série de equívocos, não só no que se refere ao estudo das línguas, mas também em relação aos métodos de ensino que passaram a ser do tipo "siga o modelo" (prática ainda comum nos dias atuais, quando se dá maior importância à criatividade individual).

Quando Chomsky lançou a sua Gramática Transformacional (1957) - e com a sua revisão (Aspects, 1965) - revolucionou o meio lingüístico porque transferiu a atenção dos estudiosos do objeto pronto (como no Estruturalismo) para o processo de produção. Sem dúvida um passo decisivo para o estudo da linguagem que, a partir daí, começou a se preocupar não só com o resultado empírico do processo lingüístico, mas com os mecanismos envolvidos na sua produção. A Lingüística passou então a ser de fato a ciência que estuda a linguagem (no seu sentido mais amplo) e não mais o estudo da língua (produto).

No entanto, a Gramática Gerativa, como a concebeu Chomsky, sempre apresentou um grande inconveniente que é o conceito de homogeneidade. Para que ela funcione é preciso, antes de mais nada, conceber um falante ideal que viva em uma sociedade ideal. Infelizmente ( ou felizmente) o nosso mundo não é homogêneo e nós, como seres humanos, menos ainda.

Além desse problema de não abranger a falta de homogeneidade do meio lingüístico, a Gramática Transformacional limita-se à sentença complexa e, como se sabe, da mesma forma que as pessoas não se comunicam apenas pela palavra, elas também não se comunicam através de sentenças. $\mathrm{Na}$ comunicação humana, então, é preciso considerar unidades maiores que, apesar de serem formadas por palavras e sentenças, operam pelo estabelecimento de relações entre elas. A análise dessas unidades maiores (enunciados, discursos, textos) não pode ficar limitada à morfo-sintaxe porque muito da significação está além desses limites, determinada por fatores extralingüísticos (os dêiticos e os anafóricos são exemplo disso), entre os quais até mesmo o silêncio pode ter significados contextuais.

A necessidade de explicar esses fenômenos extralingüísticos acabou por descortinar um leque de estudos correlatos como os da Sociolingüística e da Psicolingüística. O maior problema dessas áreas é que elas também permaneceram estanques em seus limites, tentando explicar esses fenômenos em função de um tipo de fatores ou de outro, mas nunca a partir de vários tipos de fatores ( sociais, psicológicos, ideológicos, históricos, filosóficos, etc.) ao mesmo tempo. Isso ocorre, naturalmente, pelo próprio caráter da ciência, que exige que se parta de um ponto para se chegar a um resultado, seguindo uma determinada linha, ou seja, delimitando o objeto de análise de maneira formal.

Na década de 60, Michel Pêcheux lançou a Análise Automática do Discurso (1969), criando uma nova maneira de se encarar a linguagem humana ao deslocar o ponto de partida da análise do produto pronto ou do processo interno de produção, segmentado ou não, para as condições de produção, ou seja, o objeto de estudo deixou de estar centrado na fala, na escrita ou no texto em si mesmos para recair nas 
condições, na situação, no momento de produção, invertendo a linha de raciocínio a respeito do processo de produção. A questão deixou de ser "o discurso existe independentemente do sujeito", como no Estruturalismo ou no Gerativismo, ou "determinado tipo de indivíduo produz determinado tipo de discurso", como na Sociolingüística, para ser "o porquê de determinado tipo de indivíduo produzir determinado tipo de discurso". A atenção passou do texto para o sujeito.

Esse sujeito-falante, na concepção de Pêcheux, seria resultado de um processo histórico-social e influenciado ideologicamente, o que o transforma e marca o seu discurso. Se por uma lado é facilmente concebível que um sujeito imerso em uma sociedade é influenciado por ela, por outro, a questão referente à presença de ideologia é bastante discutível. Que a ideologia está presente em todos os discursos políticos é um pressuposto bastante lógico, no entanto, em discursos não políticos, do tipo "me dá um cigarro", é bastante difícil, para não dizer impossível, perceber-se o caráter ideológico que estaria subjacente a ele.

A análise do discurso francesa privilegia sempre o discurso institucional, o que quer dizer que o trabalho de análise levará sempre em conta a situação discursiva como sendo uma situação-tipo. Por exemplo, o discurso da medicina, o discurso jurídico, o discurso científico, o discurso acadêmico, etc. são, respectivamente, aqueles que ocorrem em situações-tipo da Medicina, do Direito, da ciência, do meio acadêmico, etc. Ao se conceber que existam situações típicas, deve-se aceitar também que os sujeitos do discurso fazem parte de um universo típico de cada instituição. Mas se o sujeito é parte desse universo, deve-se propor ou que um sujeito só trafega por um universo e, então, também é um sujeito-tipo, um elemento institucional, ou que o sujeito (apesar de poder ser participante de uma instituição) trafega por várias instituições e é capaz de assumir cada um dos diversos discursos institucionais.

Os analistas franceses defendem a segunda idéia, a de que o sujeito, ao passar de um ambiente para outro, assume os discursos institucionais possíveis conforme o seu trânsito. A esse processo de adaptação discursiva dá-se o nome de assujeitamento. Esse sujeito assujeitado é então aquele que se apropria de um discurso preexistentes e faz uso dele a partir de regras também preexistentes. A conseqüência dessa concepção acaba sendo a de se supor que não existem discursos originais ou textos individuais. A esses discurso não originais dá-se o nome de intertexto. Segundo Eni Orlandi, por exemplo, os textos efetivamente produzidos são intertextos, já que para essa autora a produção discursiva de um falante sempre será atravessada por uma série de discursos preexistentes.

O que chama a atenção nessa perspectiva é o enorme reducionismo que sofre o sujeito, enquanto participante de uma situação de comunicação: por um lado ele sofre o processo de assujeitamento, assumindo não só o vocabulário e as estruturas próprias de uma instituição, mas também as próprias estratégias comunicativas inerentes a ela, e por outro, seu texto também assume idéias, vocabulário e estruturas preexistentes.

Talvez essa postura teórica se explique porque a partir do momento em que o sujeito deixa de ser sujeito e passa a ser assujeitado e o texto deixa de ser texto para ser intertexto, o que resta são estruturas já definidas, mais ou menos imutáveis e não criativas, o que vem facilitar o trabalho de análise, já que sempre é mais fácil aplicar-se dados de pesquisa sobre paradigmas do que tentar buscar explicações naquilo que não é "formalizável", naquilo que não é estrutural, mas mutável, um produto do fazer cotidiano dos falantes de uma língua. Isso implica, por outro lado, em não se conseguir analisar o discurso fora das instituições porque é nelas que ele é mais fortemente marcado. Para a análise do discurso francesa, as instituições definidas são o lugar do discurso por excelência. Daí se explica a enorme quantidade de trabalhos específicos sobre os discursos institucionais, como os citados anteriormente.

Como se pode perceber, as teorias lingüísticas, de maneira geral, não dão maior atenção ao papel individual do sujeito na produção da linguagem. As teorias formalistas geralmente vão tratá-lo como 
inexistente, ideal ou assujeitado. Em todos os casos, a individualidade do falante acaba sendo excluída dos estudos da linguagem. Uma das raras exceções é a postura teórica de M. Bakhtin, que consegue ver o sujeito como elemento participativo e atuante do processo comunicativo.

A sua postura marxista coloca o sujeito numa posição de constante interação com a sociedade e com a linguagem, a qual é vista por ele como um produto social. Como a linguagem é um produto social (e não institucional) e o sujeito é parte atuante do meio social, então ele acaba por também ser um fator de interação.

Bakhtin critica as correntes lingüísticas mais destacadas por estas não atribuírem um caráter mais social à linguagem. Como Marx não dedicou muito espaço para o estudo da linguagem em sua teoria (nem era esse o seu objetivo), Bakhtin buscou em Humbolt condições para encarar a linguagem como atividade social, reconsiderando todo o problema da linguagem dentro de uma orientação marxista geral.

É muito importante a ênfase que ele procurou dar à linguagem como atividade social, pois é a partir daí que surge a argumentação de que o processo de significação é resultado de uma ação social, o que implica em dizer que os signos são mutáveis, já que a sua existência estaria relacionada com um fazer social que não é constante ou imutável, mas sim um processo contínuo do qual toda a sociedade participa.

Cada sujeito, como parte da sociedade a que pertence, teria então o seu papel enquanto agente modificador na atividade social. Mesmo assumindo que no discurso de um sujeito possam estar presentes outros discursos anteriores, a sua forma de analisar o processo de apropriação do discurso alheio pressupõe um sujeito ativo e atuante, capaz de fazer escolhas e estabelecer estratégias. Aí reside a diferença básica entre a análise do discurso francesa e o pensamento de Bakhtin. Enquanto a primeira admite apenas um sujeito assujeitado, o segundo propõe um sujeito ativo, capaz de utilizar a linguagem para a formação de sua consciência individual e também de usar a sua individualidade para interferir no processo social da linguagem, através da sua atividade interacional constante junto à sociedade.

Em resumo, a concepção bakhtiniana atribui ao sujeito responsabilidade pelo uso que este faz da linguagem. O sujeito não é somente um divulgador de um discurso preexistente, mas um agente dentro do processo discursivo, capaz de interferir, aprimorar ou até modificar o discurso social. Esta distinção é possível pelo fato de Bakhtin, ao contrário da análise do discurso francesa, conseguir ver o discurso na sua dimensão social. Dimensão esta que contém também as dimensões institucionais e as ultrapassa, sendo parte expressiva do conjunto de relações da atividade histórico-social.

\section{BIBLIOGRAFIA}

BAKHTIN, M. Marxismo e Filosofia da Linguagem. São Paulo: Editora Hucitec,1986.

CHOMSKY, N. Aspectos da Teoria da Sintaxe. Coimbra: Américo Amado Editor,1978.

ORLANDI, E.P. Discurso e Leitura. São Paulo: Cortez Editora-Unicamp, 1988.

PÊCHEUX, M. Análise Automática do Discurso, (1969), in GADET, F. \& HAK, T. Por uma Análise

Automática do Discurso. Campinas: Unicamp, 1990. 